\title{
Inflammatory Breast Cancer Outcomes in a Contemporary Series
}

\author{
ELIZABETH PAN ${ }^{1}$, LILY TUNG $^{2}$, OMAR RAGAB $^{3}$, ELISE MOROCCO $^{1}$, JULIE WECSLER $^{2}$, \\ RICHARD SPOSTO ${ }^{4}$, AKSHARA RAGHAVENDRA ${ }^{5}$, EUGENE CHUNG ${ }^{3}$ and JULIE E. LANG $^{2}$ \\ ${ }^{1}$ Keck School of Medicine, University of Southern California, Los Angeles, CA, U.S.A.; \\ ${ }^{2}$ Los Angeles County and University of Southern California Medical Center Department of Surgery \\ and Norris Comprehensive Cancer Center, Division of Breast, Soft Tissue and Endocrine Surgery, \\ University of Southern California, Los Angeles, CA, U.S.A.; \\ ${ }^{3}$ Los Angeles County and University of Southern California Medical Center Department of Radiation Oncology \\ and Norris Comprehensive Cancer Center, University of Southern California, Los Angeles, CA, U.S.A.; \\ ${ }^{4}$ Department of Preventive Medicine and Pediatrics of Children's Hospital of Los Angeles \\ and Norris Comprehensive Cancer Center, University of Southern California, Los Angeles, CA, U.S.A.; \\ ${ }^{5}$ Department of Medicine, Division of Oncology, University of Southern California, Los Angeles, CA, U.S.A.
}

\begin{abstract}
Background. Evidence on the management of inflammatory breast cancer (IBC) is limited. This study investigated factors influencing IBC treatment outcomes such as event-free survival (EFS) and overall survival (OS). Materials and Methods: Data were collected from 173 patients with stage III non-IBC and 17 patients with IBC diagnosed at the Keck Medical Center and Los Angeles County and University of Southern California (LAC+USC) Medical Center. Cox proportional hazard regression evaluated associations between variables significant for EFS and OS. Results: On multivariate analysis, negative estrogen receptor (ER)status [hazard ratio $(H R)=1.88,95 \%$ confidence interval $(C I)=1.11-3.18, p<0.06)$ and lack of postoperative radiation treatment $(H R=2.07,95 \% C I=1.03$ $4.15, p<0.04)$ were significant for poorer EFS. High ScarffBloom-Richardson (SBR) score (HR=2.24, 95\% CI=0.79$6.36, p<0.13)$ and lack of postoperative radiation treatment to the breast $(H R=4.39,95 \% C I=0.39-49.55, p<0.23)$ were associated with lower rates of OS. Conclusion: The diagnosis of IBC has a significantly worse prognosis. Receipt of post-mastectomy radiation therapy was a significant predictor of better EFS and OS.
\end{abstract}

Correspondence to: Julie E. Lang, MD, FACS, 1450 Biggy Street, Norris Research Tower (NRT) 3505, Los Angeles, CA 90033, U.S.A. Tel: +1 3234428140. Fax: +1 3238653539, e-mail: julie.lang@med.usc.edu

Key Words: Inflammatory breast cancer, IBC, disease-free survival, DFS, overall survival.
Inflammatory breast cancer (IBC) was first identified by Lee and Tannenbaum (16), and is defined by strict diagnostic criteria of erythema and edema (peau d'orange) of the breast in the absence or presence of a discrete mass that developed over less than 6 months, involvement of greater than onethird of the breast, and biopsy-proven invasive carcinoma (1, 12). The swelling, redness, and inflammation associated with IBC is due to the buildup of tumor cells that block dermal lymphatic vessels, and rapid progression of the disease results in higher rates of recurrence, metastasis, and mortality $(18,27,28)$. Despite being the most aggressive form of breast cancer (at least a stage III disease by definition), IBC encompasses only $1-3 \%$ of all breast cancer, with limited data on treatment regimens and outcomes (30).

Previous studies have shown that poor prognostic indicators of IBC include younger age at diagnosis, poorer tumor grade, negative estrogen receptor (ER) status (2), lesser degree of pathological response in the breast and lymph nodes $(6,22,23)$, erythema involving the whole breast at initial diagnosis, and $p 53$ gene mutation $(7,21)$. Treatment recommendations for patients with IBC include trimodality therapy consisting of neoadjuvant systemic chemotherapy followed by definitive surgery and radiation therapy $(1,28)$. When compared to non-inflammatory locally advanced breast cancer, IBC is associated with more aggressive tumor characteristics. The 5-year survival rates after trimodality therapy for IBC versus non-IBC locally advanced breast cancer have been reported to be as low as 30.2 vs. $45.1 \%(p<0.001)(29)$. The aggressive clinical course of IBC makes it of particular research interest. Most of the available data has been garnered from retrospective 
and small prospective studies, and there have been several single-center studies focusing on locoregional and survival outcomes of different treatment modalities. Smoot et al. conducted a study of 156 patients with IBC treated with either chemotherapy or surgery as the initial therapy, and a disease-free survival of $21 \%$ and 5 -year survival of $42 \%$ were reported, with no significant difference in outcome between the sequences of therapy (24). In a separate retrospective series, 107 patients with IBC who received chemotherapy, underwent modified radical mastectomy, and standard fractionation radiation with daily skin bolus as part of combined-modality therapy were assessed. Locoregional control at 3 and 5 years was reported to be $90 \%$ and $87 \%$, while distant metastasis-free survival at 3 and 5 years was not as successful at $61 \%$ and $47 \%$ (10).

The patient population in our study is unique as it included patients from both an academic medical center and a public safety-net hospital and thus encompasses a particularly broad demographic. The primary aim of our study was to determine the event-free survival (EFS) and overall survival (OS) rates of our patients with stage III breast cancer controlling for IBC. Our secondary aim was to identify prognostic factors that are associated with improved OS or EFS. In addition, our study was conducted in an urban setting with a racially and socioeconomically diverse cohort where faculty are associated with a comprehensive cancer center that serves both an academic medical center and county hospital.

\section{Materials and Methods}

Data source, inclusion and exclusion criteria. Adult patients diagnosed between January 1, 2008 and December 31, 2013 with stage III (IBC and non-IBC) were identified from the tumor registries at USC Keck Medical Center and LAC+USC. Data for the cohort of 190 patients were collected through the electronic medical record system at USC Keck Medical Center and LAC-USC (Affinity, Cerner). Patients who did not receive their full course of treatment at one of the above medical centers or had a previous history of breast cancer were excluded.

Study variables. The patient variables assessed are listed in Table I, and include patient characteristics, and imaging and pathology factors. Treatment factors assessed were preoperative and postoperative chemotherapy and radiation. For post-mastectomy radiation therapy, dose to chest wall, radiation boost, regional radiation (and which lymph node chains were included), radiation technique, lymph node dose, radiation delays, time from definitive surgery to start of radiation, and time from start of chemotherapy to start of radiation were recorded.

Variables that demonstrated co-linearity on multivariate analysis were controlled for, and included ER-positive versus endocrine therapy, neoadjuvant versus adjuvant chemotherapy, and overall nodal status versus postoperative nodal status.

Statistical methods. Each characteristic variable was compared using the Chi-square to test for associations between non-IBC and IBC.
All survival analyses were compared between IBC and non-IBC. In addition, univariate analysis of all patients by IBC status for EFS and OS were performed. For all survival analyses, the starting point was the date of diagnosis. The endpoints for survival analyses were for OS, date of death; for EFS: date of local recurrence, date of regional recurrence, date of distant metastasis, date of death. All survival analyses were visualized by Kaplan-Meier curves. Survival analyses for all patients, survival curves, and 95\% confidence intervals were obtained. Survival curves were compared for statistical differences by log-rank test and hazard ratios, obtained from Cox regression modeling.

Cox regression was used to identify the risk factors that may correspond to all patients with breast cancer. Both EFS and OS were analyzed. Firstly, Cox proportional-hazards regression was carried out on each single variable and hazard ratios (HRs) were obtained, then all variables were put into one model to obtain the adjusted HRs for each variable. Finally, model selection was used to obtain the final predictive models for EFS and OS. Likelihood ratio tests were used for model selection. All statistical evaluations were performed with the STATA/SE 12.0 software package (StataCorp LLC, College Station, Texas, USA). A value of $p<0.05$ (two-tailed) was considered statistically significant.

\section{Results}

Patient characteristics. A total of 190 patients with stage III breast cancer met our inclusion criteria, and baseline patient, tumor and treatment characteristics are listed in Table I. Two patients with IBC were excluded due to metastatic disease at the time of diagnosis. The total number of patients with IBC was $17(9 \%)$ and those with non-IBC were $173(91 \%)$. The total number of patients with stage III breast cancer diagnosed at LAC-USC and Norris Comprehensive Cancer Center within our timeframe was 840 (2\% IBC). The mean age at diagnosis was 47.9 for IBC and 48.8 for non-IBC patients. The number of triple-negative patients with IBC was 7 (41\%) and non-IBC was $40(23 \%)(p=0.11)$. The majority of patients with IBC (15 out of $17,88 \%$ ) and non-IBC (139 out of $173,80 \%)$ underwent a combination of neoadjuvant chemotherapy, modified radical mastectomy surgery, and radiation therapy. One patients with IBC refused chemotherapy, and another patient did not receive radiation due to development of subcutaneous nodules. In the IBC group, 16 (94\%) received neoadjuvant chemotherapy, compared to $87(50 \%)$ in the non-IBC group $(p=0.001)$. Pathological complete response was $12 \%$ for IBC and $5 \%$ for non-IBC $(p=0.72)$. Between patients with IBC and those with non-IBC, there was no significant difference in mean age at diagnosis, ethnic distribution, ER and progesterone receptor (PR) status, human epidermal receptor 2 (HER2) status, tumor characteristics, and node positivity. Median survival times for IBC versus non-IBC were 16 and 45.6 months, respectively. The three-year OS rate of patients with IBC in our study was $80 \%$, and the 3-year EFS rate was $40 \%$.

Variables affecting EFSl. On univariate analysis of all variables from Table I stratified by IBC status, factors that 
Table I. Baseline patient and treatment characteristics.

\begin{tabular}{|c|c|c|c|c|c|}
\hline Variable & & $\mathrm{IBC}, \mathrm{n}(\%)$ & Not IBC, n (\%) & Total, n (\%) & $p$-Value \\
\hline Total & & $17(100 \%)$ & $173(100 \%)$ & $190(100 \%)$ & \\
\hline \multirow{2}{*}{ Institution } & LAC & $12(71 \%)$ & $119(69 \%)$ & $131(69 \%)$ & 0.88 \\
\hline & $\mathrm{NCCC}$ & $5(29 \%)$ & $54(31 \%)$ & $59(31 \%)$ & \\
\hline \multirow[t]{5}{*}{ Race } & Non-Hispanic White & $2(13 \%)$ & $44(26 \%)$ & $46(25 \%)$ & 0.07 \\
\hline & Hispanic & $9(56 \%)$ & $98(57 \%)$ & $107(57 \%)$ & \\
\hline & Black & $3(19 \%)$ & $6(4 \%)$ & $9(5 \%)$ & \\
\hline & Asian/Pacific Islander & $2(13 \%)$ & $19(11 \%)$ & $21(11 \%)$ & \\
\hline & Not available & $0(0 \%)$ & $4(2 \%)$ & $4(2 \%)$ & \\
\hline Mean age at diagnosis, years & & 47.9 (10.4) [17] & $48.8(12.0)[171]$ & $48.7(11.8)[188]$ & 0.77 \\
\hline \multirow[t]{3}{*}{ Estrogen receptor } & Positive & $7(41 \%)$ & $116(67 \%)$ & $123(65 \%)$ & 0.08 \\
\hline & Negative & $10(59 \%)$ & $55(32 \%)$ & $65(34 \%)$ & \\
\hline & Not available & $0(0 \%)$ & $1(1 \%)$ & $1(1 \%)$ & \\
\hline \multirow{3}{*}{ Progesterone receptor } & Positive & $5(29 \%)$ & $94(55 \%)$ & $99(52 \%)$ & 0.12 \\
\hline & Negative & $12(71 \%)$ & $77(45 \%)$ & $89(47 \%)$ & \\
\hline & Not available & $0(0 \%)$ & $1(1 \%)$ & $1(1 \%)$ & \\
\hline \multirow[t]{3}{*}{ Human epidermal growth factor 2} & Positive & $5(29 \%)$ & $35(20 \%)$ & $40(21 \%)$ & 0.66 \\
\hline & Negative & $12(71 \%)$ & $136(79 \%)$ & $148(78 \%)$ & \\
\hline & Not available & $0(0 \%)$ & $1(1 \%)$ & $1(1 \%)$ & \\
\hline \multirow[t]{3}{*}{ Hormone receptor status (ER/PR) } & Positive & $7(41 \%)$ & $118(69 \%)$ & $125(66 \%)$ & 0.06 \\
\hline & Negative & $10(59 \%)$ & $53(31 \%)$ & $63(33 \%)$ & \\
\hline & Not available & $0(0 \%)$ & $1(1 \%)$ & $1(1 \%)$ & \\
\hline \multirow[t]{3}{*}{ Tumor size - maximum dimension, $\mathrm{cm}$} & 3 & $7(41 \%)$ & $41(26 \%)$ & $48(28 \%)$ & 0.36 \\
\hline & 3 to 4 & $6(35 \%)$ & $57(37 \%)$ & $63(36 \%)$ & \\
\hline & $5+$ & $4(24 \%)$ & $58(37 \%)$ & $62(36 \%)$ & \\
\hline \multirow[t]{3}{*}{ BIRADs score } & $\leq 4$ & $2(14 \%)$ & $28(19 \%)$ & $30(19 \%)$ & 0.85 \\
\hline & 5 & $7(50 \%)$ & $74(51 \%)$ & $81(51 \%)$ & \\
\hline & 6 & $5(36 \%)$ & $43(30 \%)$ & $48(30 \%)$ & \\
\hline \multirow[t]{5}{*}{ SBR score (3-9) } & 4 or 5 & $1(7 \%)$ & $11(7 \%)$ & $12(7 \%)$ & 0.51 \\
\hline & 6 & $3(21 \%)$ & $38(25 \%)$ & $41(24 \%)$ & \\
\hline & 7 & $2(14 \%)$ & $26(17 \%)$ & $28(17 \%)$ & \\
\hline & 8 & $1(7 \%)$ & $34(22 \%)$ & $35(21 \%)$ & \\
\hline & 9 & $7(50 \%)$ & $45(29 \%)$ & $52(31 \%)$ & \\
\hline \multirow[t]{6}{*}{ Pathologic stage } & 0 & $2(13 \%)$ & $9(5 \%)$ & $11(6 \%)$ & 0.64 \\
\hline & I & $1(6 \%)$ & $8(5 \%)$ & $9(5 \%)$ & \\
\hline & II & $1(6 \%)$ & $21(13 \%)$ & $22(12 \%)$ & \\
\hline & III & $10(63 \%)$ & $104(63 \%)$ & $114(63 \%)$ & \\
\hline & IV & $1(6 \%)$ & $3(2 \%)$ & $4(2 \%)$ & \\
\hline & Not available & $1(6 \%)$ & $19(12 \%)$ & $20(11 \%)$ & \\
\hline \multirow[t]{2}{*}{ Herceptin } & Yes & $5(31 \%)$ & $34(21 \%)$ & $39(22 \%)$ & 0.37 \\
\hline & No & $11(69 \%)$ & $125(79 \%)$ & $136(78 \%)$ & \\
\hline \multirow[t]{2}{*}{ Adjuvant chemotherapy } & Yes & $0(0 \%)$ & $71(41 \%)$ & $71(37 \%)$ & 0.0008 \\
\hline & No & $17(100 \%)$ & $102(59 \%)$ & $119(63 \%)$ & \\
\hline Neoadjuvant chemotherapy & Yes & $16(94 \%)$ & $87(50 \%)$ & $103(54 \%)$ & 0.0005 \\
\hline & No & $1(6 \%)$ & $86(50 \%)$ & $87(46 \%)$ & \\
\hline Type of breast surgery & Modified radical mastectomy & $16(100 \%)$ & $108(64 \%)$ & $124(67 \%)$ & 0.07 \\
\hline & Lumpectomy & $0(0 \%)$ & $49(29 \%)$ & $49(26 \%)$ & \\
\hline & Total mastectomy & $0(0 \%)$ & $11(6 \%)$ & $11(6 \%)$ & \\
\hline & Re-excision & $0(0 \%)$ & $1(1 \%)$ & $1(1 \%)$ & \\
\hline & Not available & $0(0 \%)$ & $1(1 \%)$ & $1(1 \%)$ & \\
\hline Endocrine therapy & Yes & $5(31 \%)$ & $93(58 \%)$ & $98(56 \%)$ & 0.04 \\
\hline & No & $11(69 \%)$ & $66(42 \%)$ & $77(44 \%)$ & \\
\hline Dermal lymphatic invasion & Yes & $1(7 \%)$ & $1(1 \%)$ & $2(1 \%)$ & 0.04 \\
\hline & No & $14(93 \%)$ & $154(99 \%)$ & $168(99 \%)$ & \\
\hline Tumor histology (biopsy) & DCIS alone & $2(12 \%)$ & $11(7 \%)$ & $13(7 \%)$ & 0.72 \\
\hline & DCIS+IDCA & $2(12 \%)$ & $44(26 \%)$ & $46(25 \%)$ & \\
\hline & IDCA alone & $10(59 \%)$ & $87(51 \%)$ & $97(52 \%)$ & \\
\hline & Lobular & $2(12 \%)$ & $19(11 \%)$ & $21(11 \%)$ & \\
\hline & Other invasive & $1(6 \%)$ & $8(5 \%)$ & $9(5 \%)$ & \\
\hline Radiation therapy for breast & Yes & $15(88 \%)$ & $145(85 \%)$ & $160(85 \%)$ & 0.70 \\
\hline & No & $2(12 \%)$ & $26(15 \%)$ & $28(15 \%)$ & \\
\hline Postoperative nodal status & No & $4(25 \%)$ & $32(19 \%)$ & $36(20 \%)$ & 0.18 \\
\hline & N1 & $3(19 \%)$ & $39(23 \%)$ & $42(23 \%)$ & \\
\hline & N2 & $2(13 \%)$ & $60(36 \%)$ & $62(34 \%)$ & \\
\hline & N3 & $6(38 \%)$ & $33(20 \%)$ & $39(21 \%)$ & \\
\hline & Not available & $1(6 \%)$ & $3(2 \%)$ & $4(2 \%)$ & \\
\hline Positive nodal status (pre-op and post-op) & Yes & $16(94 \%)$ & $155(91 \%)$ & $171(91 \%)$ & 0.63 \\
\hline & No & $1(6 \%)$ & $16(9 \%)$ & $17(9 \%)$ & \\
\hline
\end{tabular}




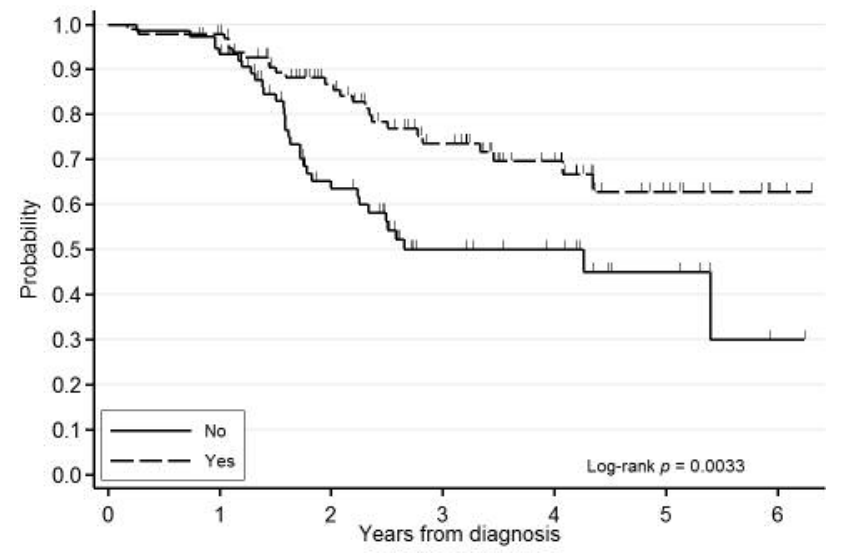

Figure 1. Kaplan-Meier event-free survival curve for patients receiving endocrine therapy.

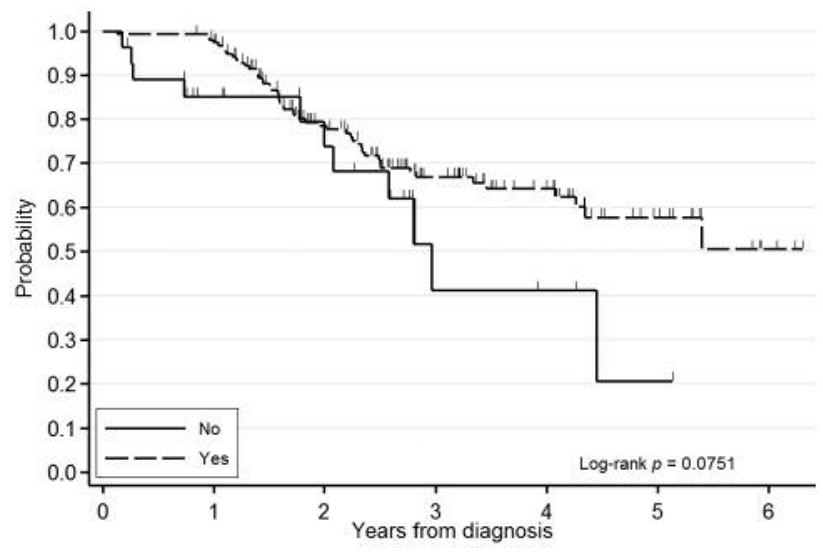

Figure 2. Kaplan-Meier event-free survival curve for radiation therapy to the breast.

were significant for lower rates of EFS were negative ER status $(\mathrm{HR}=1.96,95 \% \mathrm{CI}=1.17-3.27, p<0.01)$, lack of treatment with endocrine therapy $(\mathrm{HR}=2.01,95 \% \mathrm{CI}=1.19$ $3.41, p<0.009)$, and lack of postoperative radiation therapy to the breast $(\mathrm{HR}=2.02,95 \% \mathrm{CI}=1.04-3.95, p<0.04)$. Figures 1 and 2 show survival curves of patients treated with endocrine therapy and radiation therapy. Variables associated with a trend toward lower rates of EFS were negative PR status $(\mathrm{HR}=1.53,95 \% \mathrm{CI}=0.91-2.58, p<0.1)$, higher SBR score (trend $p=0.15)$, invasive tumor histology $(\mathrm{HR}=4.07$, $95 \% \mathrm{CI}=0.74-22.3, p<0.14)$, node-positive status $(\mathrm{HR}=1.82$, $95 \% \mathrm{CI}=0.86-3.85, p<0.11$ ), and treatment with neoadjuvant chemotherapy $(\mathrm{HR}=0.68,95 \% \mathrm{CI}=0.39-1.17, p<0.16)$.

Variables that were significant or trended toward lower rates of EFS were included in a multivariate analysis stratified by

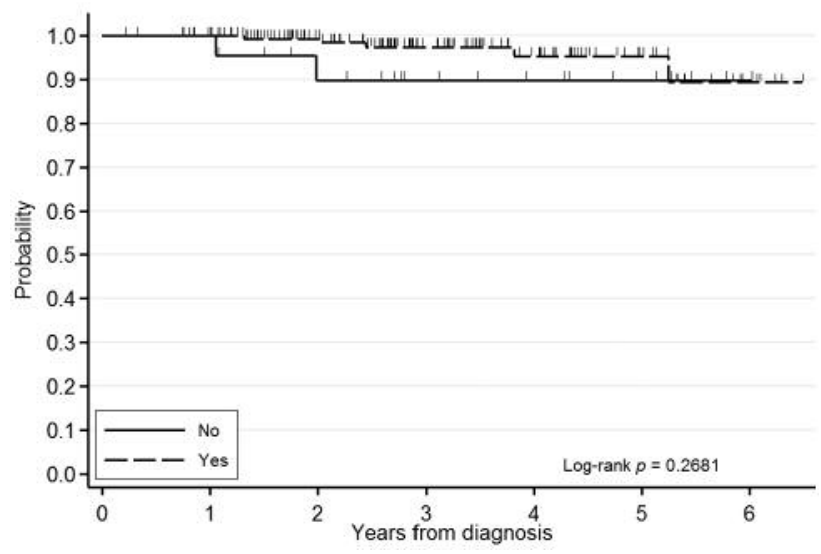

Figure 3. Kaplan-Meier overall survival curve stratified by SBR score.

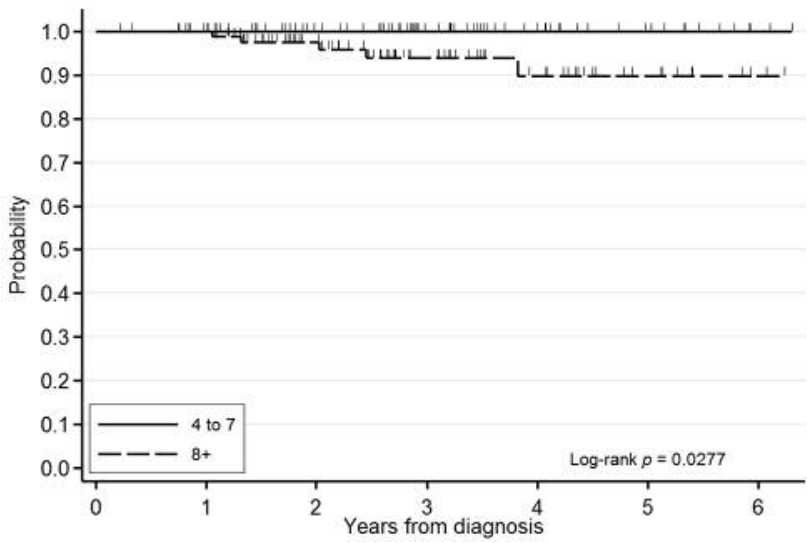

Figure 4. Kaplan-Meier overall survival curve for radiation therapy to the breast.

IBC status. On reverse stepwise multivariate analysis, negative ER status $(\mathrm{HR}=1.88,95 \% \mathrm{CI}=1.11-3.18, p<0.06)$ and lack of postoperative radiation treatment $(\mathrm{HR}=2.07,95 \% \mathrm{CI}=1.03$ $4.15, p<0.04)$ were identified as significant for EFS. On forward analysis, there were no additional significant variables. Variables affecting OS. On univariate analysis of all variables from Table I stratified by IBC status, factors that were associated with a trend toward lower rates of OS were higher SBR score (trend $p=0.09$ ) and lack of postoperative radiation therapy to the breast $(\mathrm{HR}=4.95,95 \% \mathrm{CI}=0.76$ $32.25, p<0.09)$. Kaplan-Meier survival curves for OS are shown in Figures 3 and 4 . These variables were then included in a multivariate analysis stratified by IBC status. On reverse stepwise multivariate analysis, SBR score $(\mathrm{HR}=2.24,95 \% \mathrm{CI}=0.79-6.36, p<0.13)$ and lack of 
postoperative radiation treatment to the breast $(\mathrm{HR}=4.39$, $95 \% \mathrm{CI}=0.39-49.55, p<0.23)$ were associated with a trend for lower rates of OS. There were no variables significantly associated with in IBC on multivariable analysis.

\section{Discussion}

IBC is a rare disease, and thus the study of this malignancy and its prognostic indicators is challenging. This study evaluated variables that would be potential patient, tumor, treatment and prognostic indicators of EFS and OS in stage III IBC and non-IBC.

The study findings suggest that IBC is a poor prognostic indicator when controlling for all other variables known to be significant for outcomes on univariate and multivariate analysis.

Variables significant for EFS were ER-negative status (extrapolated to be ER- and PR-negative given their colinearity on multivariate analysis) and lack of radiation treatment to the breast. The fact that hormone receptor status was a statistically significant prognostic indicator for EFS on univariate and multivariate analyses is supported by known evidence in the literature that triple-negative breast disease is a poor prognostic factor $(15,17,20,25)$. Although HER2 status was not isolated as a significant prognostic indicator, it is known that IBC is associated with higher rates of HER2 amplification, and neoadjuvant treatment with trastuzumab improves outcomes in patients with IBC (4). All HER2positive patients in our study received appropriate trastuzumab therapy. While the diagnosis of IBC was the only significant prognostic indicator for OS, a high SBR score and lack of radiation treatment to the breast trended toward worse OS rates.

There was a statistically significant survival benefit for treatment with postoperative radiation versus surgery alone when controlling for IBC in EFS, however, the CI included 1.0 for the multivariate analysis assessing OS and the sample size of non-irradiated patients was small; only two (12\%) patients with IBC and $26(15 \%)$ of those with non-IBC stage III breast cancer did not receive postoperative radiation therapy to the breast. The effect of radiation on EFS and OS cannot be fully assessed in this study, and a meta-analysis of randomized trials is needed to demonstrate this in operable breast cancer (8). Given our limited cohort of patients with IBC, our study may be underpowered to show that improved locoregional control is achieved with breast radiation (Figure 2). Bristol et al. showed that patients with a partial response to neoadjuvant chemotherapy who received higher doses of radiation (66 Gy vs. $60 \mathrm{~Gy}$ ) had significantly improved 5year locoregional control rates $(70 \%$ vs. $32 \%, p=0.04)(5)$.

The standard of care for treatment of IBC includes neoadjuvant chemotherapy followed by modified radical mastectomy and adjuvant radiation therapy to the breast.
Only one patient with IBC in our study did not receive neoadjuvant chemotherapy (patient refused chemotherapy at the time). Patients with ER-positive IBC are recommended also to receive endocrine therapy, and all patients in our study received the appropriate endocrine therapy $(11,26)$. Given the rarity of IBC combined with its aggressive nature (the majority of new diagnoses are at least stage III), this breast disease is not only difficult to treat but also associated with poor outcomes, with reported 5-year OS rates of 40$51 \%$ (9). In our study, that included patients with stage III disease primarily treated at an urban safety-net medical center, the 3-year OS rate of patients with IBC in our study was $80 \%$, and the 3 -year EFS rate was $40 \%$; these rates are not very different from the published contemporary literature (13). The higher OS rate in our cohort compared to previously reported data may be due to the relatively young age of our patient population (mean age 49 years), which might be associated with fewer comorbidities, however, younger age is often correlated with high-grade disease. For both IBC and non-IBC, the majority of patients received postoperative radiation to the breast $(88 \%$ and $85 \%$, respectively), and radiation was associated with improved EFS and OS. Our findings are in agreement with those of a single institutional study with 192 patients with IBC which demonstrated that women treated with neoadjuvant chemotherapy, mastectomy, and post-mastectomy radiation had better 5-year OS compared to those treated with single or dual-modality therapy (51\% and $24 \%$, respectively) (5). The fact that $60 \%$ of our population had recurrence events suggests that the 3-year mark may be too early to assess survival status secondarily to IBC. However, 5-year OS rates for patients with IBC still tend to be lower than those for patients with locally advanced non-IBC regardless of multimodality therapy (62\% vs. $81 \%)$ (14).

According to the National Comprehensive Cancer Center (19) guidelines, standard neoadjuvant therapy should include an anthracycline-based regimen and a taxane (19). For our IBC cohort, five patients $(29 \%)$ received a taxane-based regimen, $11(65 \%)$ received both anthracycline and taxane, and one $(6 \%)$ refused all chemotherapy. For non-IBC patients, three $(2 \%)$ received an anthracycline-based regimen, 27 (16\%) received taxane-based, and $126(73 \%)$ received both anthracycline and taxane. Documentation of the specific chemotherapy regimen was not available for the remaining 17 patients $(9 \%)$.

The limitations of this study include it being a small cohort of patients with IBC available to compare to those with non-IBC. This reduced the power of our study and may have skewed the survival analyses to favor variables that were more closely linked with IBC, such as neoadjuvant chemotherapy (patients who received neoadjuvant chemotherapy had worse outcomes compared to those receiving adjuvant chemotherapy). However, despite the 
discrepancy in group sizes between those with IBC and nonIBC, baseline patient, tumor and treatment characteristics were not significantly different. In addition, we reported 3 year OS rates, and there may have been more deaths from disease in the IBC group compared to the non-IBC group.

Of note, our cohort is unique in that the population was relatively young (mean age at diagnosis of 49 years) and diverse, with 56\% Hispanic, 19\% African-American, 13\% Asian and 13\% non-Hispanic White. Few studies have focused on race as a potential prognostic indicator, and our study suggests that race may not play a significant role in outcomes, given that it was not isolated as a significant prognostic variable. Although data from larger-scale studies have shown that African-American patients tended to have lower pathological complete response rates and worse outcomes compared to Caucasian patients, this is one of the first studies that we are aware of that focuses upon outcomes for locally advanced and IBC in a predominantly Hispanic population (3).

\section{References}

1 AJCC Cancer Staging Handbook. 7th edition. American Joint Committee on Cancer, Chicago, IL 2010.

2 Anderson WF, Chu KC, and Chang S: Inflammatory breast carcinoma and noninflammatory locally advanced breast carcinoma: distinct clinicopathologic entities? J Clin Oncol 21: 2254-2259, 2003.

3 Andic F, Godette K, O'Regan R, Zelnak A, Liu T, Rizzo M, Gabram S, and Torres M: Treatment adherence and outcome in women with inflammatory breast cancer: does race matter? Cancer 117: 5485-5492, 2011.

4 Baselga J, Semiglazov V, Manikhas GM, Eiermann W, Lluch A, Tjulandin S, Feyereislova A, Vanhauwere B, Valagussa P, and Gianni L: 2030 ORAL Efficacy of neoadjuvant trastuzumab in patients with inflammatory breast cancer: data from the NOAH Phase III trial. EJC Supplements 5: 193.

5 Bristol IJ, Woodward WA, Strom EA, Cristofanilli M, Domain D, Singletary SE, Perkins GH, Oh JL, Yu TK, Terrefe W, Sahin AA, Hunt KK, Hortobagyi GN, and Buchholz TA: Locoregional treatment outcomes after multimodality management of inflammatory breast cancer. Int J Radiat Oncol Biol Phys 72: 474-484, 2008.

6 Buzdar AU, Singletary SE, Booser DJ, Frye DK, Wasaff B, and Hortobagyi GN: Combined modality treatment of stage III and inflammatory breast cancer. M.D. Anderson Cancer Center experience. Surg Oncol Clin N Am 4: 715-734, 1995.

7 Chevallier B, Asselain B, Kunlin A, Veyret C, Bastit P, and Graic Y: Inflammatory breast cancer. Determination of prognostic factors by univariate and multivariate analysis. Cancer 60: 897902, 1987.

8 Clarke M, Collins R, Darby S, Davies C, Elphinstone P, Evans V, Godwin J, Gray R, Hicks C, James S, MacKinnon E, McGale P, McHugh T, Peto R, Taylor C, Wang Y, and Early Breast Cancer Trialists' Collaborative G: Effects of radiotherapy and of differences in the extent of surgery for early breast cancer on local recurrence and 15-year survival: an overview of the randomised trials. Lancet 366: 2087-2106, 2005.
9 Cristofanilli M, Valero V, Buzdar AU, Kau SW, Broglio KR, Gonzalez-Angulo AM, Sneige $N$, Islam $R$, Ueno NT, Buchholz TA, Singletary SE, and Hortobagyi GN: Inflammatory breast cancer (IBC) and patterns of recurrence: understanding the biology of a unique disease. Cancer 110 : 1436-1444, 2007.

10 Damast S, Ho AY, Montgomery L, Fornier MN, Ishill N, Elkin $\mathrm{E}$, Beal K, and McCormick B: Locoregional outcomes of inflammatory breast cancer patients treated with standard fractionation radiation and daily skin bolus in the taxane era. Int J Radiat Oncol Biol Phys 77: 1105-1112, 2010.

11 Davies C, Godwin J, Gray R, Clarke M, Cutter D, Darby S, McGale P, Pan HC, Taylor C, Wang YC, Dowsett M, Ingle J, and Peto R: Relevance of breast cancer hormone receptors and other factors to the efficacy of adjuvant tamoxifen: patientlevel meta-analysis of randomised trials. Lancet 378: 771-784, 2011.

12 Dawood S, Merajver SD, Viens P, Vermeulen PB, Swain SM, Buchholz TA, Dirix LY, Levine PH, Lucci A, Krishnamurthy S, Robertson FM, Woodward WA, Yang WT, Ueno NT, and Cristofanilli M: International expert panel on inflammatory breast cancer: consensus statement for standardized diagnosis and treatment. Ann Oncol 22: 515-523, 2011.

13 Gonzalez-Angulo AM, Hennessy BT, Broglio K, MericBernstam F, Cristofanilli M, Giordano SH, Buchholz TA, Sahin A, Singletary SE, Buzdar AU, and Hortobagyi GN: Trends for inflammatory breast cancer: is survival improving? Oncologist 12: 904-912, 2007.

14 Hance KW, Anderson WF, Devesa SS, Young HA, and Levine PH: Trends in inflammatory breast carcinoma incidence and survival: the surveillance, epidemiology, and end results program at the National Cancer Institute. J Natl Cancer Inst 97: 966-975, 2005.

15 Harris EE, Schultz D, Bertsch H, Fox K, Glick J, and Solin LJ: Ten-year outcome after combined modality therapy for inflammatory breast cancer. Int J Radiat Oncol Biol Phys 55: 1200-1208, 2003.

16 Lee BJ, and N. Tannenbaum Inflammatory carcinoma of the breast: a report of twenty-eight cases from the breast clinic of Memorial Hospital. Surg Gynecol Obstet 39: 580-595, 1924.

17 Liu J, Chen K, Jiang W, Mao K, Li S, Kim MJ, Liu Q, and Jacobs LK: Chemotherapy response and survival of inflammatory breast cancer by hormone receptor- and HER2defined molecular subtypes approximation: an analysis from the National Cancer Database. J Cancer Res Clin Oncol 143: 161168, 2017.

18 Low JA, Berman AW, Steinberg SM, Danforth DN, Lippman ME, and Swain SM: Long-term follow-up for locally advanced and inflammatory breast cancer patients treated with multimodality therapy. J Clin Oncol 22: 4067-4074, 2004.

19 NCCN: Clinical Practical Guidelines in Oncology (NCCN Guidelines) Breast Cancer Version 3.2015 2015.

20 Palangie T, Mosseri V, Mihura J, Campana F, Beuzeboc P, Dorval T, Garcia-Giralt E, Jouve M, Scholl S, Asselain B et al: Prognostic factors in inflammatory breast cancer and therapeutic implications. Eur J Cancer 30A: 921-927, 1994.

21 Riou G, Le MG, Travagli JP, Levine AJ, and Moll UM: Poor prognosis of $\mathrm{p} 53$ gene mutation and nuclear overexpression of p53 protein in inflammatory breast carcinoma. J Natl Cancer Inst 85: 1765-1767, 1993. 
22 Rouesse J, Friedman S, Sarrazin D, Mouriesse H, Le Chevalier T, Arriagada R, Spielmann M, Papacharalambous A, and MayLevin F: Primary chemotherapy in the treatment of inflammatory breast carcinoma: a study of 230 cases from the Institut GustaveRoussy. J Clin Oncol 4: 1765-1771, 1986.

23 Rouzier R, Extra JM, Klijanienko J, Falcou MC, Asselain B, Vincent-Salomon A, Vielh P, and Bourstyn E: Incidence and prognostic significance of complete axillary downstaging after primary chemotherapy in breast cancer patients with $\mathrm{T} 1$ to $\mathrm{T} 3$ tumors and cytologically proven axillary metastatic lymph nodes. J Clin Oncol 20: 1304-1310, 2002.

24 Smoot RL, Koch CA, Degnim AC, Sterioff S, Donohue JH, Grant CS, Barnes SA, Gullerud RE, Hobday TJ, and Farley DR: A single-center experience with inflammatory breast cancer, 1985-2003. Arch Surg 141: 567-572; discussion 572-563, 2006.

25 Somlo G, Frankel P, Chow W, Leong L, Margolin K, Morgan R, Jr., Shibata S, Chu P, Forman S, Lim D, Twardowski P, Weitzel J, Alvarnas J, Kogut N, Schriber J, Fermin E, Yen Y, Damon L, and Doroshow JH: Prognostic indicators and survival in patients with stage IIIB inflammatory breast carcinoma after dose-intense chemotherapy. J Clin Oncol 22: 1839-1848, 2004.

26 Stearns V, Ewing CA, Slack R, Penannen MF, Hayes DF, and Tsangaris TN: Sentinel lymphadenectomy after neoadjuvant chemotherapy for breast cancer may reliably represent the axilla except for inflammatory breast cancer. Ann Surg Oncol 9: 235242,2002
27 Therasse P, Mauriac L, Welnicka-Jaskiewicz M, Bruning P, Cufer T, Bonnefoi H, Tomiak E, Pritchard KI, Hamilton A, Piccart MJ, and Eortc: Final results of a randomized phase III trial comparing cyclophosphamide, epirubicin, and fluorouracil with a dose-intensified epirubicin and cyclophosphamide + filgrastim as neoadjuvant treatment in locally advanced breast cancer: an EORTC-NCIC-SAKK multicenter study. J Clin Oncol 21: 843-850, 2003.

28 Ueno NT, Buzdar AU, Singletary SE, Ames FC, McNeese MD, Holmes FA, Theriault RL, Strom EA, Wasaff BJ, Asmar L, Frye D, and Hortobagyi GN: Combined-modality treatment of inflammatory breast carcinoma: twenty years of experience at M.D. Anderson Cancer Center. Cancer Chemother Pharmacol 40: 321-329, 1997.

29 van Uden DJ, Bretveld R, Siesling S, de Wilt JH, and BlankenPeeters CF: Inflammatory breast cancer in the Netherlands; improved survival over the last decades. Breast Cancer Res Treat 162: 365-374, 2017.

30 Wingo PA, Jamison PM, Young JL, and Gargiullo P: Populationbased statistics for women diagnosed with inflammatory breast cancer (United States). Cancer Causes Control 15: 321-328, 2004.

Received May 17, 2017

Revised May 24, 2017

Accepted July 26, 2017 